\title{
Delayed density-dependent and rainfall effects on reproductive parameters of an irruptive rodent in semiarid Chile
}

\author{
Mauricio LIMA and Fabian M. JAKSIC
}

Lima M. and Jaksic F. M. 1998. Delayed density-dependent and rainfall effects on reproductive parameters of an irruptive rodent in semiarid Chile. Acta Theriologica 43: $225-234$

We examined the influence of density-dependent and density-independent factors on reproductive processes of leaf-eared mouse Phyllotis darwini (Waterhouse, 1837) in a semiarid region of Chile subjected to El Niño-driven precipitation. This species undergoes periodic irruptions apparently triggered by unusually high precipitation. The effects of density and precipitation were analyzed statistically regarding the following reproductive parameters: fraction of reproductive females, reproductive number (juveniles + reproductive females), per capita reproductive rates, and reproduction index based on long-term data ( 10 years). The fraction of reproductive females was affected positively by precipitation during the preceding winter and negatively by population density one year before. The reproduction index and the reproductive rate was positively affected by population density the previous year. In addition, the reproductive number was positively correlated with precipitation levels. The $P$. darwini population studied was affected by delayed density-dependent and density-independent factors in reproductive parameters. We propose that both destabilizing effects on reproductive rates of $P$. darwini may be major factors underlying the frequent outbreaks of this mouse observed in semiarid regions of Chile.

Departamento de Ecología, Pontificia Universidad Católica de Chile, Casilla 114-D, Santiago, Chile, e-mail: emlima@genes.bio.puc.cl, fjaksio@genes.bio.puc.cl; fax: 56-2-686 2615

Key words: Density-dependence, reproduction, precipitation, outbreaks, Chile

\section{Introduction}

Many small mammal populations display dramatic fluctuations in their numbers, and for long, ecologists have attempted to explain the causes of that variability (Elton 1924, Stenseth 1995). However, only recently have theoretical and empirical field studies been used to synthesize ideas from different schools of thought (Stenseth et al. 1996a). The basic framework for analyzing population dynamics is to perceive temporal population variability as the outcome of density-dependent and density-independent factors acting on population processes (Royama 1992). Therefore, the first step to gain insight in population dynamics is 
to determine how these two factors affect population processes such as mortality, natality, and dispersal rates (Sharov 1992).

Many researchers have monitored the demography of fluctuating microtine populations. Still, the importance of density-dependent and density-independent factors on population processes remains unsettled. For instance, density-dependent effects on mortality have been reported for some microtine species (Mihok et al. 1985, Ostfeld and Canham 1995), whereas other species demonstrate density-independent mortality (Krebs and Myers 1974, Gaines and McClenaghan 1980). Similarly, disparate results have been obtained for reproductive rates, with some species displaying density-dependent effects (Ostfeld and Canham 1995), while others appear unaffected by density (Batzli and Pitelka 1971, Rodd and Boonstra 1984). On the other hand, there is evidence that both types of factors influence reproductive output in some vole and mice populations (Pucek et al. 1993).

Much less is known about population factors and processes underlying fluctuations of Neotropical rodents. Adler and Beatty (1997) stated that the reproductive activity of the Neotropical forest rodent Proechimys semispinosus is dependent on population density and the resource levels. No such certainty has been expressed in documenting the sporadic outbreaks that some rodent populations undergo in semiarid regions of western South America, although it has been suggested that they are associated with unusual precipitation levels (Hershkovitz 1962, Fulk 1975, Pearson 1975, Péfaur et al. 1979, Meserve and Le Boulengé 1987, Jiménez et al. 1992, Jaksic et al. 1996, 1997). Nevertheless, demographic analyses are lacking to determine how factors affect basic population processes of those irrupting species. Here, we present a study on the leaf-eared mouse Phyllotis darwini (Waterhouse, 1837), a 50-g cricetid rodent that experiences population outbreaks in semiarid regions of western South America associated with unusual rainy years produced by El Niño Southern Oscillation (ENSO) disturbances. The implied causality is that rainfall variation (ENSO periodicity) drives primary productivity and thus small mammal numbers through increased food availability (Jaksic et al. 1997), both as herbage and seeds (Gutiérrez et al. 1993). In addition, we have found that density-dependent effects are important for determining the per capita population rate of change of this species (Lima and Jaksic 1998).

In sum, although the existence of potential factors regulating leaf-eared mouse populations is recognized, the particular mechanisms operating on the different demographic processes are not fully understood. Consequently, the aim of this study is to examine the effects of density-dependent and density-independent factors on reproductive processes of $P$. darwini, based on a long-term study conducted in a semiarid locality of Chile. By analyzing population data of this species we attempt to determine whether the fraction of reproductive females, the number of juveniles + number of reproductive females, the reproduction index, and the reproductive rate are influenced by density-dependent and/or density-independent factors. 


\section{Material and methods}

\section{Study area and data}

The study site was Las Chinchillas National Reserve, at Aucó ( $\left.31^{\circ} 30^{\prime} \mathrm{S}, 71^{\circ} 06^{\prime} \mathrm{W}\right), 300 \mathrm{~km}$ north of Santiago, Chile. The climate is semiarid, with scarce rainfall concentrated in winter months. Mean annual precipitation is $175 \mathrm{~mm}$, but with high interannual variability (Jaksic et al. 1996). The vegetation is a thorn-scrub, with species composition depending on solar exposure (Jiménez et al. 1992). Slopes that face to the north (equatorial) receive higher solar radiation and have sandy soils with scattered gravel patches and rock outcrops. Because of the xeric character of these slopes, grasses are scarce, but cacti, bromeliads and sclerophyllous shrubs are abundant. In contrast, slopes that face to the south (polar) receive less solar radiation and thus are more mesic; there are no cacti or bromeliads, and a different assemblage of shrubs is present.

Four subpopulations of $P$. darwini were monitored through mark-recapture procedures on one xeric and one mesic slope in each of two creeks $2 \mathrm{~km}$ apart: "El Cobre" and "El Grillo". Trapping was undertaken from October 1987 to December 1991 on a bimonthly basis, and from this period onto October 1996 on quarterly basis, but only in "El Cobre" creek. Each seven by seven trapping grid had stations separated by $15 \mathrm{~m}$, thus covering an area of 105 by $105 \mathrm{~m}$ (including a boundary strip of 7.5 $\mathrm{m}$ ), or $1.1 \mathrm{ha}$. Grids were equipped with Sherman traps, which were activated simultaneously on the xeric and mesic slopes during five consecutive nights. All traps were kept permanently in the field and closed when not in use. We baited traps with rolled oats, and checked them every morning. Each individual captured was marked with a metal ear tag, and its body mass, sex, and reproductive condition were determined. $P$. darwini density was estimated as the minimum number of individuals known alive divided by 1.1 ha, during each trapping session.

\section{Statistical analyses}

We used ten years (1987-1996) of spring records from the two habitat types (xeric and mesic) at "El Cobre" creek, and five years (1987-1991) of spring records in the two habitats at "El Grillo" creek. First, we defined the demographic parameters used as response variables. The annual fecundity of females $\left(\mathrm{F}_{\mathrm{t}}\right)$ was defined as the fraction of total adult females that were reproductively active (pregnant or lactating) during the breeding season (September-December; see Meserve and Le Boulengé 1987). When the number of females captured was lower than 5, we did not use this data point in the analysis. Then we defined $J_{t}$ as the number of juveniles (individuals $<35 \mathrm{~g}$; Meserve and Le Boulengé 1987) captured during the breeding season (September-December). The other reproductive parameters used here were: the reproductive number $=$ number of females (pregnant + lactating) + number of juveniles, and the reproduction index $=$ number of reproductive females (pregnant + lactating) + number of juveniles/total population size (see Pucek et al. 1993). The reproductive rate of females $\left(R_{t}\right)$ was defined as the natural logarithm of the ratio between the number of juveniles captured during the end of the breeding season (December-February at "El Cobre" creek and January-March at "El Grillo" creek) and the number of adult females captured two months earlier (October at "El Cobre" creek and November at "El Grillo" creek). This parameter represents the per capita production of juveniles. We estimated $20 \mathrm{~d}$ of gestation and $20 \mathrm{~d}$ to reach the body mass of $20 \mathrm{~g}$ (ie, mean size of first capture).

We used simple linear regression analyses to test the effects of the following independent variables: total population density during Spring of the same year (October-November) $\left(\mathrm{N}_{\mathrm{t}}\right)$, total population density during Spring of the year before $\left(\mathrm{N}_{\mathrm{t}-1}\right)$, and annual accumulated precipitation before the reproductive season. We used a stepwise regression to determine the significance of the annual accumulated precipitation when the density-dependence terms were significant. First regressing the response variable against $\mathrm{N}_{t}$ and then determining whether adding $\mathrm{N}_{t-1}$, and the precipitation term, reduced significantly the unexplained variance. 


\section{Results}

We analyzed data from 1014 captures (627 of adult females and 387 of juveniles), which corresponded to 518 different individuals (254 adult females and 264 juveniles).

We found that direct density-dependence $\left(\mathrm{N}_{\mathrm{t}}\right)$ had no effects on the fraction of reproductive females of $P$. darwini $\left(\mathrm{R}^{2}=0.14, F=3.15, \mathrm{df}=1,20, p=0.091\right)$, but it had a significant negative relationship with population density the year before $\left(\mathrm{N}_{\mathrm{t}-1}\right)\left(\mathrm{R}^{2}=0.41, F=10.92, \mathrm{df}=1,16, p=0.004\right.$; Fig. 1). Consideration of the annual precipitation accumulated during the previous winter increased the

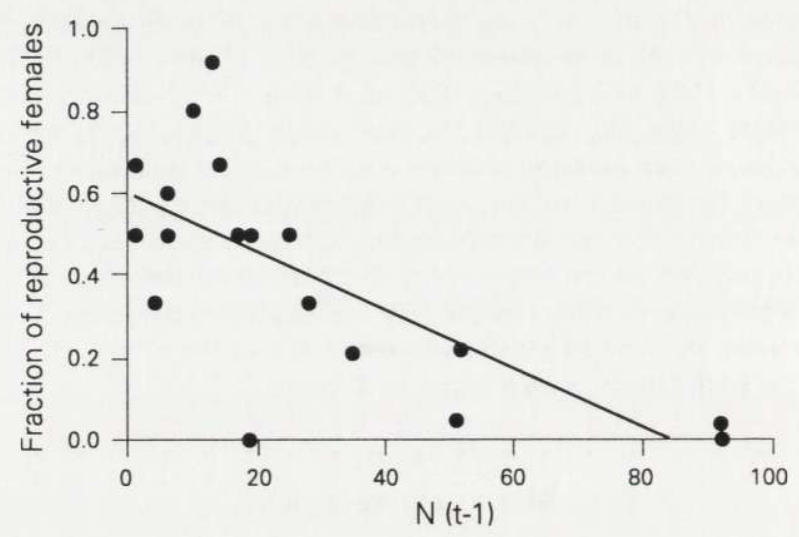

Fig. 1. Relationship between the fraction of reproductive females (pregnant + lactating females/total adult females) captured during the breeding season in Chile (October at "El Cobre" and November at "El Grillo" creeks) and population density one year before in the same creeks.

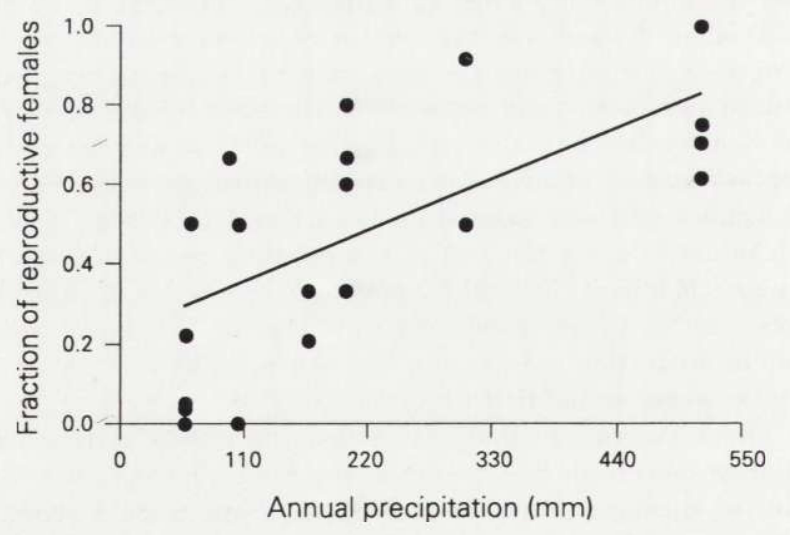

Fig. 2. Relationship between the fraction of reproductive females (pregnant+lactating females/total adult females) captured during the breeding season in Chile (October at "El Cobre" and November at "El Grillo" creeks) and the annual accumulated precipitation. 
variance explained by the regression $\left(\mathrm{R}^{2}=0.54, F=8.85, \mathrm{df}=2,15, p=0.003\right.$; Fig. 2). Consequently, the reproductive number $\left(\mathrm{R}^{2}=0.73, F=82.80, \mathrm{df}=1,30\right.$, $p<0.0001$; Fig. 3) was positively correlated with the precipitation that fell during the previous winter. On the other hand, we found that the reproductive rate of females was not related with total population density $\left(\mathrm{R}^{2}=0.004, F=0.11, \mathrm{df}=\right.$ $1,28, p=0.75$ ), but there was a negative relationship between reproductive rates and the population density the year before $\left(\mathrm{R}^{2}=0.40, F=15.65, d f=1,28, p=\right.$ 0.001 ; Fig. 4). Adding the precipitation term to the step-wise regression did not increase significantly the variance explained on reproductive rates $\left(R^{2}=0.061\right.$,

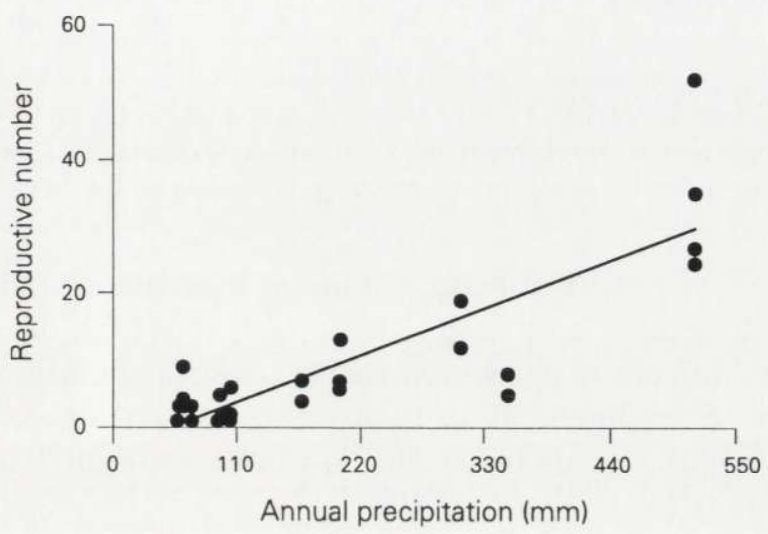

Fig. 3. Relationship between the reproductive number (reproductive females captured during October at "El Cobre" and November at "El Grillo" creeks + the number of juveniles captured from December to February at "El Cobre" creek, and January-March at "El Grillo" creek) and the annual accumulated precipitation in a Chilean locality.

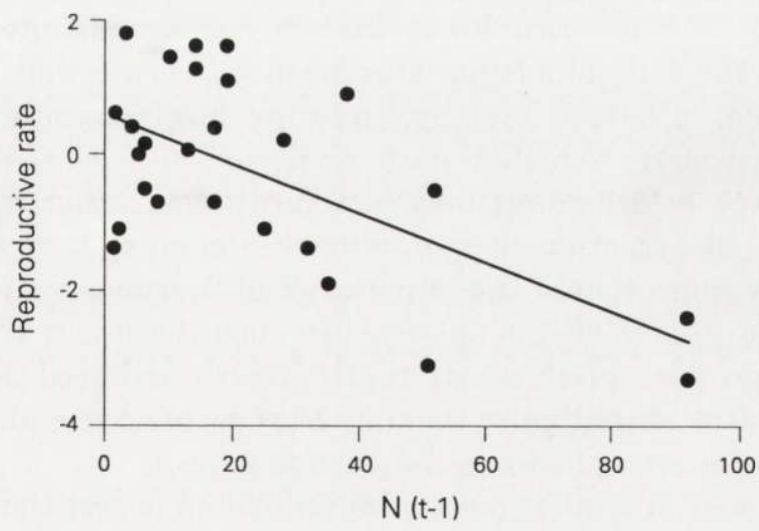

Fig. 4. Relationship between the reproductive rate $[\log$ (number of juveniles /number of adult females] and population density one year before (October or November depending on the creek) in a Chilean locality. 


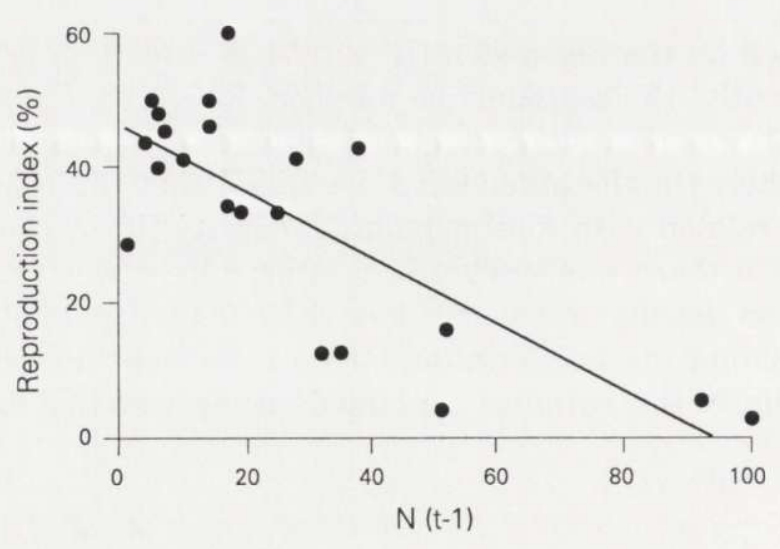

Fig. 5. Relationship between the reproduction index (reproductive number/total population density) and population density one year before (October or November depending on the creek) in a Chilean locality.

$F=1.83, \mathrm{df}=1,28, p=0.19)$. Lastly, we found that the reproduction index was not correlated with population density $\left(\mathrm{R}^{2}=0.04, F=1.09, \mathrm{df}=1,30, p=0.30\right)$, but there was a significant negative relationship with population density the year before $\left(\mathrm{R}^{2}=0.44, F=20.26, \mathrm{df}=1,30, p<0.001\right.$; Fig. 5). Addition of the precipitation term did not increase the variance explained by the regression $\left(\mathrm{R}^{2}=0.02, F=0.57, \mathrm{df}=1,30, p=0.46\right)$.

\section{Discussion}

Population dynamics of the leaf-eared mouse in semiarid regions of Chile is characterized by large population irruptions associated with an interannual pattern of rainfall variability (Jiménez et al. 1992, Meserve et al. 1995, Jaksic et al. 1997). Densities of $P$. darwini during breeding seasons (September-December) varied from 1 to 100 individuals/ha. Our results indicate that density one year previous the breeding season and precipitation levels account for most of the explained variation in reproductive parameters of $P$. darwini. The existence of a significant positive relationship between the precipitation fallen during the previous winter, the fraction of reproductive females, and the reproductive number, is a clear indication of the importance of this density-independent factor on reproductive processes of this species. Because there is a strong influence of precipitation on primary productivity (herb growth and seed density) (Jaksic et al. 1997), this result highlights the importance of external disturbances on reproductive parameters of leaf-eared mouse females.

Several experimental studies have been conducted to test the effects of density and food supplementation on reproductive traits of rodents (Andrzejewski 1975, Andrzejewski and Mazurkiewicz 1976, Cole and Batzli 1978, Ford and Pitelka 1984, Desy and Batzli 1989, Mihok and Boonstra 1992, Ostfeld and Canham 1995, 
Löfgren et al. 1996). These studies have shown that the fraction of reproductive fernales is affected by density and food addition. However, we did not find direct density-dependent effects on the fraction of reproductive females, although evidence for microtine rodents suggests important direct density-dependent influences on this reproductive parameter (Ostfeld and Canham 1995). Likewise, other studies detected a strong effect of food supplementation on reproduction (Desy and Batzli 1989, Boutin 1990). As a consequence, the positive effects of the amount of rainfall during the previous winter on some reproductive parameters suggest that food plant quality and abundance may play a key role in determining reproductive parameters. Jaksic et al. (1997) emphasized the importance of unusually high precipitations produced by El Niño Southern Oscillation (ENSO) events in determining primary productivity of semiarid ecosystems of northern Chile. These authors quantified substantial increases in the cover and seed production of ephemeral plant species after ENSO disturbances. Within this framework, we postulate that fecundity rates of $P$. darwini females may be fostered by precipitation levels. In fact, we found that precipitation influenced the fraction and the number of reproductive females, and hence the number of juveniles. The increase in juvenile numbers may be associated with the increase in reproductive females.

What is interesting is the presence of important density-dependent effects acting in a delayed manner on the different reproductive parameters analyzed. The fraction of reproductive females, the reproduction index, and the reproductive rate were largely determined by the population density the year before. Interestingly, the reproduction index and the reproductive rates were not influenced by the rainfall pattern. The reproduction index represents the proportion of reproductive females and juveniles in the population. Consequently, one possible cause for the non-significant relationship between rainfall and reproduction index may be the increase of adult immigration after rainy winters (Lima and Jaksic unpublished work). On the other hand, the reproductive rate is an estimate of the number of juveniles produced by a female during the breeding season, and involves the litter size, litter number and the survival rates of the offspring. Therefore, our results suggest that rainfall does not influence these parameters. This is a interesting result, because an increase in the number of litters produced by females after unusually rainy winters has been postulated as one of the mechanisms triggering population outbreaks of this species (Meserve and Le Boulengé 1987, Jiménez et al. 1992). Several studies have found ample evidence of social interactions in microtine rodents, including spatial behavior, territoriality and aggressive encounters (Krebs and Myers 1974, Boonstra and Rodd 1983, Taitt and Krebs 1985, Stenseth and Ims 1993). Overall, these mechanisms seem to produce instantaneous density-dependent effects on reproductive processes. For instance, recent experimental work found only direct density-dependent effects on reproduction and recruitment of Microtus pennsylvanicus (Ostfeld et al. 1993, Ostfeld and Canham 1995). In contrast, we did not find direct density-dependent effects on reproductive parameters of $P$. darwini. Reproductive rates and the reproduction 
index were only determined by population density the year before, which reinforces the idea that delayed effects are one of the main factors shaping reproductive processes. Indeed, delayed density-dependence has been detected in several rodent species (Turchin 1993, Bjørnstad et al. 1995, Stenseth et al. 1996a, b, Saitoh et al. 1997) and in P. darwini in this same locality (Lima and Jaksic 1998) using time series analysis.

The biological mechanisms causing delayed density-dependence are poorly understood and controversial. In addition, delayed density-dependent factors are an important destabilizing force in populations (Royama 1992). Therefore, the existence of delayed density-dependent factors on reproductive processes may have important consequences on the population dynamics of the leaf-eared mouse. For instance, the absence of direct density-dependent effects on reproductive processes could lead to high seasonal growth rates during the breeding period. In fact, during outbreaks, which are triggered in spring after unusually rainy winters, population density increases toward late summer (Jiménez et al. 1992, Jaksic et al. 1997). Therefore, high population densities during the breeding season are unable to restrain the reproductive activities. The causes of the delayed density-dependent effects on reproduction are not clear, but one plausible mechanism may be mouse-resource dynamics (Taitt and Krebs 1985). Recent experimental evidence showed strong plant-herbivore interactions in snowshoe-hare (Krebs et al. 1995) as well as in rodent populations (Agrell et al. 1995). The latter study showed delayed density-dependent effects on the fraction of reproductively active females and the number of juveniles of field voles Microtus agrestis. On the other hand, Ostfeld et al. (1993) found that plant-vole interactions did not show a delayed density-dependent effect in Microtus pennsylvanicus. Our study shows that high density during the previous year reduces significantly the potential for reproduction in $P$. darwini, which reinforces the idea of delayed effects on food quantity or quality (see Agrell et al. 1995 and references therein). The rodent P. darwini is herbivorous-granivorous (Meserve and Le Boulengé 1987), hence high grazing and seed predation pressures during high-density periods may have delayed negative effects on plant cover, quality, and on the seed bank. These speculations call for an experimental approach.

We conclude that the $P$. darwini population studied was affected by density-dependent and density-independent factors in its reproductive parameters. In particular, rainfall affected positively the repoductive number and the fraction of reproductive females, while population density the previous breeding season affected negatively the fraction of reproductive females, the reproduction index, and the reproductive rates. Consequently, our results supported the view that destabilizing density-independent (precipitation) and delayed density-dependent factors acting on reproductive rates of $P$. darwini may be major factors underlying its population outbreaks in semiarid regions of Chile (Jiménez et al. 1992, Jaksic et al. 1996). Further studies are needed to evaluate the biological causes of delayed density-dependent factors on specific demographic processes. 
Acknowledgements: M. Lima acknowledges a fellowship from the Vicerrectoría Académica of P. Universidad Católica de Chile for supporting his graduate studies. This research was funded by grants FONDECYT 296-0034 to ML and 196-0319 to FMJ, who also acknowledges the support of the Presidential Chair in Science.

\section{References}

Adler G. H. and Beatty R. P. 1997. Changing reproductive rates in a Neotropical forest rodent, Proechimys semispinosus. Journal of Animal Ecology 66: 472-480.

Agrell J., Erlinge S., Nelson J., Nilsson C. and Persson I. 1995. Delayed density-dependence in a small-rodent population. Proceedings of the Royal Society of London B 262: 65-70.

Andrzejewski R. 1975. Supplementary food and the winter dynamics of bank vole populations. Acta Theriologica 20: 23-40.

Andrzejewski R. and Mazurkiewicz M. 1976. Abundance and food supply and size of the bank vole home range. Acta Theriologica 21: 237-253.

Batzli G. O. and Pitelka F. A. 1971. Condition and diet of cycling populations of the California vole, Microtus californicus. Journal of Mammalogy 52: 141-163.

Bjørnstad O. N., Falck W. and Stenseth N. C. 1995. A geographic gradient in small rodent density fluctuations: a statistical modelling approach. Proceedings of the Royal Society of London B 262: 127-133.

Boonstra R. and Rodd F. H. 1983. Regulation of breeding density in Microtus pennsylvanicus. Journal of Animal Ecology 62: 757-780.

Boutin S. A. 1990. Food supplementation experiments with terrestrial vertebrates: patterns, problems, and the future. Canadian Journal of Zoology 68: 203-220.

Cole F. R. and Batzli G. O. 1978. Nutrition and population dynamics of the prairie vole, Microtus ochrogaster in central Illinois. Journal of Animal Ecology 48: 455-470.

Desy E. A. and Batzli G. O. 1989. Effects of food availability and predation on prairie vole demography: a field experiment. Ecology 70: 411-421.

Elton C. 1924. Fluctuations in the numbers of animals. British Journal of Experimental Biology 2: 119-163.

Ford R. G. and Pitelka F. A. 1984. Resource limitation in a population of the California vole. Ecology 65: $122-135$

Fulk G. W. 1975. Population ecology of rodents in the semiarid shrublands of Chile. Occasional Papers, The Museum, Texas Tech University 33: 1-40.

Gaines M. S. and McClenaghan L. R. 1980. Dispersal in small mammals. Annual Review of Ecology and Systematics 11: 163-196.

Gutiérrez J. R., Meserve P. L., Jaksic F. M., Contreras L. C., Herrera S. and Vásquez H. 1993. Structure and dynamics of vegetation in a Chilean arid thorn scrub community. Acta Oecologica 14: 271-285.

Hershkovitz P. 1962. Evolution of Neotropical cricetine rodents (Muridae), with special reference to the Phyllotine group. Fieldiana, Zoology 46: 1-524.

Jaksic F. M., Feinsinger P. and Jiménez J. E. 1996. Ecological redundancy and long-term dynamics of vertebrate predators in semiarid Chile. Conservation Biology 10: 252-262.

Jaksic F. M., Silva S. I., Meserve P. L. and Gutiérrez J. R. 1997. A long-term study of vertebrate predator responses to an El Niño (ENSO) disturbance in western South America. Oikos 78: 341-354.

Jiménez J. E., Feinsinger P. and Jaksic F. M. 1992. Spatiotemporal patterns of an irruption and decline of small mammals in northcentral Chile. Journal of Mammalogy 73: 356-364.

Krebs C. J. and Myers J. H. 1974. Population cycles in small mammals. Advances in Ecological Research 8: 267-399.

Krebs C. J., Boutin S., Boonstra R., Sinclair A. R. E., Smith J. N. M., Dale M. R. T., Martin K. and Turkington R. 1995. Impact of food and predation on the Snowshoe hare cycle. Science 269: $1112-1115$. 
Lima M. and Jaksic F. M. 1998. Population variability among three small mammal species in the semiarid Neotropics: the role of density-dependent and density-independent factors. Ecography 21: $175-180$

Löfgren O., Hörnfeldt B. and Eklund U. 1996. Effect of supplemental food on a cyclic Clethrionomys glareolus population at peak density. Acta Theriologica 41: 383-394.

Meserve P. L. and Le Boulengé E. 1987. Population dynamics and ecology of small mammals in the northern Chilean semiarid region. Fieldiana, Zoology, New Series 39: 413-431.

Meserve P. L., Yunger J. A., Gutiérrez J. E., Contreras L. C., Milstead W. B., Lang B. K., Cramer K. L., Herrera S., Lagos V. O., Silva S. I., Tabilo E. L., Torrealba M. A. and Jaksic F. M. 1995. Heterogeneous responses of small mammals to an El Niño southern oscillation event in northcentral semiarid Chile and the importance of the ecological scale. Journal of Mammalogy 76: 580-595.

Mihok S. and Boonstra R. 1992. Breeding performance in captivity of meadow voles (Microtus pennsylvanicus) from decline- and increase- populations. Canadian Journal of Zoology 70: 1561-1566.

Mihok S., Turner B. N. and Iverson S. L. 1985. The characterization of vole population dynamics. Ecological Monographs 55: 399-420.

Ostfeld R. S. and Canham C. D. 1995. Density-dependent processes in meadow voles: an experimental approach. Ecology 76: 521-532.

Ostfeld R. S., Canham C. D. and Pugh S. R. 1993. Intrinsic density-dependent regulation of vole populations. Nature 366: 259-261.

Pearson O. P. 1975. An outbreak of mice in the coastal desert of Peru. Mammalia 39: 375-386.

Péfaur J. E., Yáñez J. L. and Jaksic F. M. 1979. Biological and environmental aspects of a mouse outbreak in the semiarid region of Chile. Mammalia 43: 313-322.

Pucek Z., Jędrzejewski W., Jędrzejewska B. and Pucek M. 1993. Rodent population dynamics in a primeval deciduous forest (Białowieża National Park) in relation to weather, seed crop, and predation. Acta Theriologica 38: 199-232.

Rodd F. H. and Boonstra R. 1984. The spring decline in the meadow vole, Microtus pennsylvanicus: the effect of density. Canadian Journal of Zoology 56: 17-27.

Royama T. 1992. Analytical population dynamics. Chapman and Hall, London.

Saitoh T., Stenseth N. C. and Bjørnstad O. N. 1997. Density-dependence in fluctuating grey-sided vole populations. Journal of Animal Ecology 66: 14-24.

Sharov A. A. 1992. The life-system approach: a system paradigm in population ecology. Oikos 63: $485-494$

Stenseth N. C. 1995. The long-term study of voles, mice and lemmings: homage to Robert Collett. Trends in Ecology and Evolution 10: 512.

Stenseth N. C., Bjørnstad O. N. and Falck W. 1996a. Is spacing behavior coupled with predation causing the microtine density cycle? A synthesis of current process-oriented and pattern-oriented studies. Proceedings of the Royal Society of London B 263: 1423-1435.

Stenseth N. C., Bjørnstad O. N. and Saitoh T. 1996b. A gradient from stable to cyclic populations of Clethrionomys rufocanus in Hokkaido, Japan. Proceedings of the Royal Society of London B 263: $1117-1126$.

Stenseth N. C. and Ims R. A. 1993. Population dynamics of lemmings: temporal and spatial variation - an introduction. [In: The biology of Lemmings. N. C. Stenseth and R. A. Ims, eds]. Academic Press, London: 61-96.

Taitt M. J. and Krebs C. J. 1985. Population dynamics and cycling. [In: Biology of New Word Microtus. R. H. Tamarin, ed]. Special Publication No. 8, American Society of Mammalogists: 567-620.

Turchin P. 1993. Chaos and stability in rodent population dynamics: evidence from non-linear time-series analysis. Oikos 68: 167-172.

Received 22 May 1997, accepted 5 January 1998. 